\title{
Discourse-sensitive clitic-doubled dislocations in heritage Spanish
}

\author{
Tania Leal Méndez ${ }^{\mathrm{a}}$, Jason Rothman ${ }^{\mathrm{b}}$, Roumyana Slabakova ${ }^{\mathrm{a}, \mathrm{c},{ }^{*}}$ \\ a The University of lowa, USA \\ ${ }^{\mathrm{b}}$ The University of Reading, United Kingdom \\ ${ }^{\mathrm{c}}$ The University of Southampton, United Kingdom
}

Received 1 December 2012; received in revised form 20 December 2013; accepted 8 January 2014

\begin{abstract}
This experimental study tests the predictions of the Interface Hypothesis (Sorace, 2011, 2012) using two constructions whose appropriateness depends on monitoring discourse information: Clitic Left Dislocation and Fronted Focus. Clitic Left Dislocation relates a dislocated and clitic-doubled object to an antecedent activated in previous discourse, while Fronted Focus does not relate the fronted constituent to a discourse antecedent. The Interface Hypothesis argues that speakers in language contact situations experience difficulties when they have to integrate syntactic with discourse information. We tested four groups of native speakers on these constructions: Spanish monolinguals, bilinguals with more than 7 years residence in the US, intermediate and advanced proficiency heritage speakers. Our findings suggest that attrition has not set in the adult L2 bilingual speakers, and that the heritage speakers perform similarly to the monolingual and the adult sequential bilingual natives.
\end{abstract}

(C) 2014 Elsevier B.V. All rights reserved.

Keywords: Interface hypothesis; Syntax-discourse; Heritage speakers; Clitics; Spanish

\section{Introduction}

In recent years, the field of language acquisition has seen a steadily growing interest in a subset of bilinguals referred to as heritage speakers (HSs). In the context of North America, the term "Heritage Speaker" has been broadly understood as referring to a bilingual speaker of a non-majority language who has acquired this language naturalistically within a majority language societal context (e.g. Montrul, 2004, 2008; Polinsky, 2007; Rothman, 2007, 2009; Silva-Corvalán, 1994; Toribio, 2001). ${ }^{1}$ For instance, heritage speakers have either grown up speaking Spanish, Hindi, or Russian natively in their country of origin before immigrating at an early age, or in the U.S. or Canada after their parents settled in the new country. Chronologically, English is introduced as their second language, but it becomes their dominant language in adulthood. The heritage language can either be an exclusive L1 or one of the L1s in the context of simultaneous

\footnotetext{
* Corresponding author at: Department of Modern Languages, Building 65, University of Southampton, Southampton SO17 1BF, United Kingdom. Tel.: +44 0238059223.

E-mail addresses: roumyana-slabakova@uiowa.edu, R.Slabakova@soton.ac.uk (R. Slabakova).

1 In recent years, the term "heritage speaker" has been increasingly used outside of the context of the United States and Canada. Historically, however, other terms have been used in Europe, Australia, and other loci, including "generation 1.5," "background language bilinguals," and "minority language bilinguals." Differences in terminology in this regard are just that, provided the inclusion criteria for heritage language bilinguals apply. As discussed in Rothman (2009), all heritage speakers are bilinguals, but not all bilinguals are heritage speakers; the type of language contact of the bilingual situation delimits inclusion.
} 
bilingualism (2L1). It is important to highlight from the outset that one should not confuse or conflate language dominance with either nativeness or acquisition chronology. Language dominance notwithstanding, HSs are native speakers of the heritage language precisely because they acquire it in a socially nurturing environment in early childhood. Any competence differences between adult HSs and monolinguals, which can be demonstrated through experimental scrutiny, do not change the fact that the HSs acquired this language as a native L1.

With this in mind, it is understandable that much of the research on heritage language acquisition has focused on describing and explaining difference. ${ }^{2}$ The heritage language is-typically-the heard and spoken family language, which means that its distribution, once the majority language is introduced, is situation-specific and restricted. The introduction of the majority language may occur in a simultaneous or successive fashion. According to Montrul (2008), these factors can cause arrested development in the heritage language or what she and her colleagues have labeled incomplete acquisition. Moreover, HSs primarily receive input from speakers-first-generation immigrants and other heritage secondgeneration speakers-who are themselves living in a language contact situation. Thus, attrition (individual and crossgenerational) is likely to affect the input HSs receive (see Sorace, 2004, 2012; Rothman, 2007, 2009; Pascual y Cabo and Rothman, 2012 for discussion). These factors contribute to variable input both in terms of quantity and quality. Such variation is not characteristic of the environment of naturalistic monolingual learners, at least not to the same degree. ${ }^{3}$ Together, input and experience constitute the deterministic variables for language acquisition, loss, and maintenance that have been used to explain HS competence outcomes (Montrul, 2008; Pires and Rothman, 2009; Pascual y Cabo and Rothman, 2012). Factoring in the extensive contact with the majority (societal) language throughout the lifespan of HSs, it should not be surprising to find that HS adults fall into varying degrees of proficiency in the heritage language (Montrul, 2004; Montrul and Potowski, 2007), with the typical case being that the heritage language is the less dominant of the two. HSs are linguistically quite diverse, ranging from so-called "overhearers" (Au et al., 2002) to very advanced speakers (Montrul, 2004). Indeed, this diversity constitutes one of the difficulties in defining heritage speakers as a group.

Perhaps the most well known case of heritage languages in the context of the US is that of Spanish. The HSs we have tested in this experiment, for instance, were exposed to Spanish as their first language when they were infants. Some were born in Spanish-speaking countries and then immigrated to the US with their families when they were very young. Others were born in the US but were exposed to the home and immediate community language (Spanish) exclusively until they were enrolled in daycare or pre-school. ${ }^{4}$ Thus, during the first years of their lives, many of these speakers were exposed to linguistic input comparable to that which monolingual Spanish native speakers receive. While it is important to note that this is not necessarily the experience of all HSs, who may receive less input because one parent may not be a Spanish speaker or because they may receive English input from siblings, this does not change the fact that they acquire the language as a first language.

Let us elaborate on that point. While there might not be one definition of "Native Speaker" that is universally accepted, it is uncontroversial to assume that native speakers learn their native language naturalistically and in infancy. It is based on these two factors that we consider HSs to be native speakers of the heritage language. While it is often the case that the native language is also the language of the majority and of the cultural community, this does not necessarily need to be the case. Furthermore, while native speakers can be monolingual, monolingualism is clearly not a prerequisite for nativeness. Indeed, the issue of equating monolingualism with nativeness is not new and has been discussed elsewhere (e.g. Piller, 2001; Rothman, 2008; Rothman and Treffers-Daller, 2014).

Finally, there is the issue of frequency in the input. It is safe to say that no one would question nativeness in monolinguals if a given community (or section thereof) provided infants with less or more input than another. This has been found to be the case for different socioeconomic backgrounds in the U.S. (Hart and Risley, 1995), a difference that may be compensated for with intervention (Suskind et al., 2013). Similarly, we would not question that the so-called "balanced" simultaneous bilinguals would be native speakers of these languages. Therefore, while we acknowledge that not all HSs may receive the same amount of input as monolinguals, we reason that receiving less input alone does not strip HSs of their native status as far as the heritage language is concerned.

An important difference between HSs and monolingual speakers comes from the HSs' subsequent exposure to English, which eventually becomes their dominant language. As exposure to English increases in early childhood, the

\footnotetext{
${ }^{2}$ We use the term difference throughout because we believe this to be the least evaluative term. We do not view difference to be necessarily divergent or target-deviant per se. In the spirit of Pascual y Cabo and Rothman (2012) and others, we do not view HS differences from monolinguals as anything more than a set of descriptive facts.

${ }^{3}$ To be sure, monolingual children are also exposed to variable input. However, such variation is not usually the result of language contact and its attrition effects. In other words, monolinguals do not receive the majority of their input from speakers who themselves have limited contact with their native language community.

${ }^{4}$ As is well known, there are communities in the US, for example, parts of Miami, New York, Chicago, Los Angeles, New Mexico, and Texas, where Spanish is the dominant language. This balance shifts almost inevitably for individual HSs upon entering school where English is the majority language of education and newly formed social relationships.
} 
amount of Spanish input is progressively reduced, sometimes extremely so. Furthermore, they are deprived of exposure to certain grammatical properties that form part of diverse registers and language varieties of Spanish. Many of these registers and grammatical properties are imparted via formal education in Spanish, an education that monolinguals receive and HSs normally do not. In the case of the HSs in this study, Spanish remains a domestic language to them, spoken to parents and grandparents. Typically, the HSs speak English to peers and siblings, in school, and at work. At least in part due to this unbalanced bilingualism, the underlying linguistic system of their mother tongue, Spanish, can either deteriorate/attrite (Polinsky, 2007, 2011), arrest its development early on despite quality input (Montrul, 2008), or have no chance to develop, in certain regards, like the system of monolinguals. This must be the case for at least some properties, if we take seriously the possible asymmetries in input quality between the input that HSs and monolinguals receive. In this regard, research suggests that input-related differences can obtain either due to input that reflects a reduced spectrum of registers (Rothman, 2007; Pires and Rothman, 2009) or to input that reflects previous attrition in the grammar of the first-generation input providers (Sorace, 2004, 2012; Pascual y Cabo and Rothman, 2012). In both cases, the input that is unavailable to the HSs constitutes positive evidence for certain grammatical structures that are normally acquired by a typical monolingual and might not form part of the HS grammar.

Indeed, previous research has uncovered multiple grammatical differences between monolingual and HS grammars, specifically in the work of Montrul and colleagues (e.g. Montrul, 2008; Montrul and Potowski, 2007) and Polinsky (e.g. Polinsky, 1997, 2011). However, it is not necessarily the case that all domains of the HS grammar are inevitably different from the grammar of monolinguals. While finding differences in subparts of the grammar, Montrul's work also shows target monolingual-like knowledge in others (e.g. Montrul, 2004). Other researchers have also shown that, for certain properties, HSs demonstrate knowledge that is indistinguishable from that of monolinguals (e.g. Pires and Rothman, 2009). A theory of HS competence should certainly strive to explain, in the most principled way possible, areas where heritage and monolingual performance converges or diverges.

In this article, we test the predictions of the Interface Hypothesis (IH) for HS Spanish (cf. Montrul and Polinsky, 2011) and examine whether properties at the syntax-discourse interface are particularly vulnerable for this group of bilinguals, as the $\mathrm{IH}$ predicts. To do this, we examine knowledge of linguistic constructions related to discourse felicitousness, building on previous work examining similar domains in English-native L2 Spanish (e.g. Valenzuela, 2005, 2006; Slabakova et al., 2011, 2012). Our study aims to increase the diversity of acquisition conditions discussed in the literature on reference ( $L 1 A, L 2 A, 2 L 1 A)$ while highlighting the fact that the linguistic development of reference computation may be dependent on the linguistic input. Finally, we address the theoretically relevant notion of how stable discourse-related knowledge is in monolingual and adult-bilingual Spanish controls (possible L1 attriters), the latter having acquired English well after puberty. Our findings point to this knowledge being essentially the same in monolingual, heritage, and adult sequential bilingual native speakers.

\section{The Interface Hypothesis}

\subsection{Main tenets}

At its core, the Interface Hypothesis makes a linguistically principled distinction between internal and external interfaces. Within a modular view of language (e.g. Fodor, 1983; Jackendoff, 2002), interfaces embody contact points where modules of language interact with each other or with other cognitive domains. This connection is vital because the output of one module is necessarily the input for another. Internal interfaces (e.g. syntax-semantics, syntax-morphology, phonology-morphology, and syntax-morphology) involve only those interactions between language modules, while external interfaces involve interactions between linguistic and non-linguistic cognitive systems. The IH predicts that processing limitations inherent to bi- and multilingualism affect properties at external interfaces. Furthermore, the $\mathrm{IH}$ predicts that these limitations will either remain a source of residual optionality (linguistic indeterminacy) even at the L2/HS near-native level, or else result in emerging optionality in L1 attrition subjects.

The current version of the $\mathrm{IH}$ (Sorace, 2011) places much of the burden of explanation for native/near-native asymmetries on issues related to language processing. Drawing on the concept of inhibitory control (Green, 1986), and in light of research showing that all systems in a bilingual mind are simultaneously activated even when one is contextually unnecessary (see Bialystok, 2009 for review), the IH suggests that there is an inherent cognitive cost to bilingualism, as the inhibition of a first language is assumed to be burdensome on the processor. In a series of psycholinguistic experiments involving diverse methodologies, including eye tracking and brain imaging, Marian and colleagues (Spivey and Marian, 1999; Marian et al., 2003) present evidence that dual language activation in bilinguals causes languages to compete. Even when linguistic input is presented in one language (be it the L1 or L2), both L1 and L2 show evidence of activation. Increased bilingual experience (i.e. experience managing the interference caused by the presence of an additional language), however, has been presumed to improve bilinguals' ability to inhibit one language. 


\subsection{Heritage speakers and the Interface Hypothesis}

Sorace has addressed what she considers to be invalid extensions of the $\mathrm{IH}$ to certain populations, observing: "the hypothesis is not about intermediate stages of L2 development or inter-generational L1 attrition" (Sorace, 2011:26). However, one of the most appealing facets of the $\mathrm{IH}$ is precisely that it uses a principled linguistic distinction that has found support across diverse bilingual populations. ${ }^{5}$ In support of the $\mathrm{IH}$, Sorace has presented evidence from attrition (e.g. Tsimpli et al., 2004), near-native L2 populations (e.g. Belletti et al., 2007), and child bilingualism (e.g. Sorace et al., 2009), while excluding "intermediate stages" of L2 and "intergenerational" attrition. White (2011) argues that Sorace's (2011) position is "unnecessarily restrictive" if we consider that there is no a priori justification to designate the development of an L2 learner as fundamentally different from that of a child bilingual-the expectation is that both groups would experience similar interface problems.

Montrul and Polinsky (2011) have also raised some objections regarding Sorace's exclusion of "intergenerational attrition," precisely because HSs were once child bilinguals (consecutive or sequential), which is a category that Sorace accepts as falling under the $\mathrm{IH}$. Montrul and Polinsky argue: "if the $\mathrm{IH}$ uses as its database the changes that are found in near-native speakers, it is not unreasonable to think that the same changes will take place in the "stage ahead", i.e., heritage speakers" (p. 59). Sorace (2012) responds:

The $\mathrm{IH}$ claims that during the initial stages of the attrition process in individual speakers removed from their original community, the ability to rapidly coordinate syntactic and pragmatic/contextual information becomes inconsistent, but the speakers' grammatical representations do not change. These speakers then provide input affected by attrition to second generation speakers (i.e. heritage speakers), who may acquire a different grammar from that of their parents: this is a different stage of the attrition process and does not present the same characteristics as those identified by the IH (see also Sorace, 2004; Rothman, 2007, 2009). Montrul and Polinsky are right in claiming that heritage speakers are an important testing ground for the $\mathrm{IH}[\ldots$. . , as long as the differences between individual and generational attrition are clear (Sorace, 2012:213-14).

Thus, according to the $\mathrm{IH}$, the linguistic performance of $\mathrm{HSs}$ can be affected by two distinct factors. The first is the impact that language contact (bilingualism, more generally) could have on syntax-discourse interface properties in the language of the HS input providers (i.e. the first generation of immigrants) because these speakers themselves may be undergoing L1 attrition. The second is the impact of bilingualism itself directly on the second generation (namely, the HSs). Hence any changes to the input quality for discourse-related properties would result in the HSs displaying less sensitivity to appropriate grammatical choices in various discourse contexts.

In our study, we address these issues straightforwardly by using two distinct control groups: (i) monolingual Spanish speakers tested in their country of origin and (ii) native Spanish, English-L2 adult sequential bilinguals who have lived outside of their native country for at least seven years and are thus vulnerable to L1 attrition. The crucial distinction between the adult late L2-bilingual control group and the HS group lies in the fact that the former acquired English as an L2 after puberty while receiving formal instruction in their native Spanish, being Spanish-dominant from infancy through early adulthood.

Because Sorace does not object to the $\mathrm{IH}$ being applied to HSs as long as there is an indication that the input received for a specific property has not undergone change, we set out to investigate whether the speakers that provide input for the HSs perform differently than monolingual Spanish controls. Crucially, our data will show that, for the properties tested, both control groups (monolinguals and adult L2 bilinguals) perform indistinguishably. Given that there are no differences for CLLD across any of the groups, we reason that L1 attrition has not affected the input HSs receive for this specific property. This crucial comparison allows us to test the IH in HSs. Our results show that the HSs' performance was not significantly different from the control groups', thus showing convergence with what the literature describes as the monolingual standard. Overall, these results do not support the predictions outlined by the $\mathrm{IH}$.

\section{Clitic Left Dislocation and Fronted Focus in Spanish}

In the current study, we investigate the acquisition of a discourse-sensitive dislocation and a fronting operation in Spanish: Clitic Left Dislocation (CLLD) and Fronted Focus (FF). ${ }^{6}$ In CLLD, dislocated constituents are topics (i.e. entities already activated in the discourse). As is well known, definitions of topic abound. Notions such as "aboutness," "discourse

\footnotetext{
${ }^{5}$ But see Rothman (2009), Ivanov (2012), and others for conflicting results.

${ }^{6}$ CLLD seems to be ubiquitous in most, if not all, varieties of Spanish. Indeed, most analyses of CLLD have implicitly assumed no dialectal differences in this area. However, it should be noted that there are no corpora studies that back up this very common assumption. Regarding FF, López (2009) conjectures that it might not be present in the Mexican variety. However, our results do not seem to confirm this conjecture.
} 


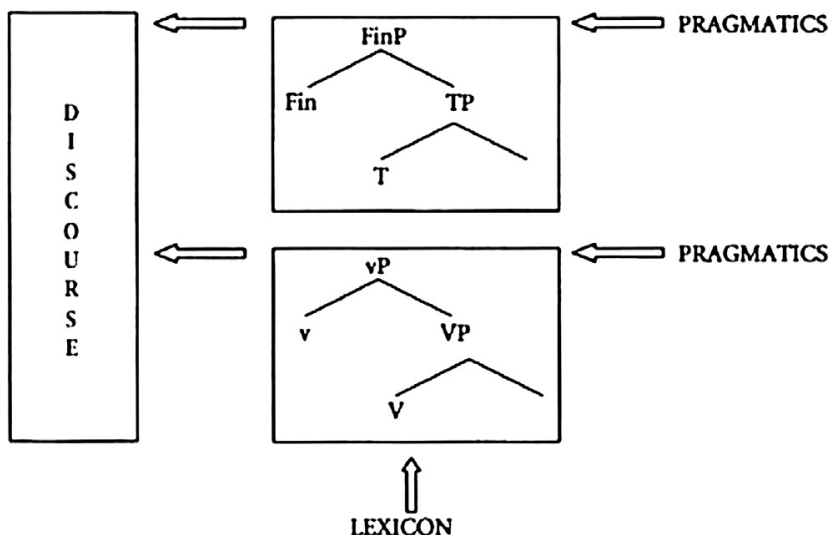

Fig. 1. López' model: interaction of syntactic objects with pragmatics.

Table 1

Feature bundles and syntactic constructions in López's (2009) Model.

\begin{tabular}{lll}
\hline & [+contrast $]$ & [-contrast] \\
\hline [+anaphor] & Clitic Left Dislocation (CLLD) & Clitic Right Dislocation (CLRD) \\
-anaphor] & Fronted Focus (FF) & Rheme \\
\hline
\end{tabular}

referent," "discourse oldness," "context-boundness," "shared knowledge," or "discourse salience" are often invoked in these definitions. Moreover, the expression of topic varies widely among languages, which can mark topic lexically, phonologically, morphologically, or syntactically. Casielles-Suárez (2004) suggests that, in fact, a unitary (cross-linguistic) definition of topics does not exist, as the characterization of topic in one language might be inadequate to define the same notion in another language.

The syntactic analysis we adopt in our study is López (2009). López rejects notions like "Topic" and "Focus" as merely descriptive and proposes an intermediate (pragmatic) level of representation between syntactic structures and discourse. The syntactic derivation proceeds in phases (Chomsky, 2001), yielding at the end of each phase-vP (verb Phrase) and FinP (Finite Phrase)-a syntactic object $\Sigma$. The pragmatics module then assigns the relevant discourse features, $[ \pm a$ (naphor)] and [ $\pm \mathrm{c}$ (ontrast)], to constituents located in syntactic positions at the phase edge, yielding object $\Sigma$ [p]. Discourse anaphors (obligatorily) take a local antecedent while being in a discourse-structural asymmetry with respect to their dependent. ${ }^{7}$ The second binary feature, contrast, opens up a variable in the quantification domain. These pragmatic structures are subsequently assembled into longer units of text in the discourse module. The overall model is illustrated in Fig. 1.

Elements that move to the edge of the VP and agree with a doubling clitic are assigned the feature [+a]; elements which move to FinP are assigned the feature $[+c]$. Non-dislocated elements receive no pragmatic features. This system thus defines different combinations of syntactic constructions and discourse feature bundles. Spanish clitic dislocations have the feature [+anaphor] in common, differing only in contrastivity (Table 1). Fronted Focus and CLLD differ in the [ \pm a] feature.

CLLD displays an interesting semantic relationship between the dislocated constituent and its antecedent. This semantic relationship can be one of identity, subset/superset, set-set member, or part/whole. Examples (López, 2009) of these relationships are below.

Context: What did you do with the furniture?

Subset

Las mesas las traje en la mañana...

the tables Cl.acc bring.PAST.1sg in the morning

'The tables, I brought in the morning...'

\footnotetext{
${ }^{7}$ Following Villalba (2000), anaphors should be explicitly mentioned in the discourse or else be abundantly prominent in the context but, crucially, they cannot be the answer to wh-questions.
} 
(2)

(3) Context:

What did you do with the tables? Las mesas las traje en la mañana... What did you do with the tables? La blanca la puse adentro... the white $\mathrm{Cl}$. acc put.PAST.1sg inside 'I put the white one inside...'

(4) Context: What shall we do with the table? It is too big! Mira, las patas, las doblas así... Look the legs Cl.acc fold.PRES.2sg this-way. 'Look, you can fold the legs like this...'
Identity

Set-membership

Part/whole

Going back to the feature bundles in Lopez's model (Table 1), note that CLLD and FF differ in one feature only: (discourse) anaphor. This means that while CLLD requires a discourse antecedent (thus being [+a]), FF does not. Therefore, the dislocated constituent in FF cannot be an entity that is already activated in the discourse (i.e. a topic). Example (5) illustrates this fact.

Context: I am glad that Arturo cleaned the bathroom.

Fronted Focus

LA COCINA limpió Arturo. El resto de la casa sigue sucia.

the kitchen he-cleaned $A$ the rest of the house continues dirty

'It was the kitchen that Arturo cleaned. The rest of the house is still dirty.'

Note in (5) that FF does not allow for a clitic. Thus, while FF and CLLD differ in only one pragmatic feature value, syntactically, these constructions differ in the presence of a clitic. ${ }^{8}$ Another important difference is the special intonation that accompanies the FF constituent.

\section{Predictions about HS knowledge}

We set out to examine whether participants show evidence of sensitivity to the discourse-appropriateness of CLLD and FF. In order to ensure that the HSs participating in the study demonstrated knowledge of the syntax of clitics, passing a clitic test was a requirement for inclusion in the experiment. Given the fact that HSs are bilinguals by definition, the IH predicts that even at very advanced levels, HSs should show evidence of residual optionality. We will argue that because our results did not show evidence of these expected differences, these results are not consistent with the predictions of the $\mathrm{IH}$. If HS acquisition is affected by cross-generational attrition as Sorace (2012) notes, then we should be able to tease this confound apart by comparing two control groups, as discussed explicitly in Section 2.2. Given this background, we offer the following juxtaposed predictions:

Hypothesis A. HSs will demonstrate behavior consistent with the IH

Evidence in support of Hypothesis A would include data showing differences between the HS groups and the controls for judgments of CLLD. Further evidence supporting the IH would include data showing that all three groups are different from one another, with the general trend showing more indeterminacy in the following way: Spanish natives (L2 English adults) showing more indeterminacy than monolinguals but less so than HSs, who would show the greatest degree of indeterminate knowledge.

Hypothesis B. HSs will demonstrate behavior inconsistent with the $\mathrm{IH}$

HSs will show no difference in their knowledge of CLLD as compared to monolinguals. Supportive evidence for Hypothesis B would be found if none of the groups perform differently from one another, since this would suggest that language attrition has not set in, at least not for the property under investigation.

\section{Experimental study}

\subsection{Participants}

A total of ninety-four participants, all native speakers of Spanish, completed a battery of online tests uploaded to a server maintained by an independent online survey service. Thirty-one speakers from a variety of countries (14 Mexico, 7

\footnotetext{
${ }^{8}$ Roughly, López's model requires elements [+a] to have an agreement relation between the dislocated constituent and the head of the phase. Because FF has no clitic, it does not get marked as [+a]. The reader is directed to Slabakova et al. (2012) for a more detailed description.
} 
Cuba, 4 Colombia, 3 Puerto Rico, 2 Spain, and 1 Peru) constituted the control group for the experiment. The control group was further divided into two subgroups, depending on whether they were monolingual Spanish speakers or late L2 English bilinguals (possible L1 attriters). The monolingual speakers ( $n=14$, mean age 43.2, 6 females, 8 males) were all speakers of Mexican Spanish; they completed the battery of tests in their home country. The participants in the late L2 bilingual group ( $n=17$, mean age 35.9, 13 females, 4 males) were native speakers of Spanish who had come to reside in the U.S. in adulthood. At the time of testing, we required that the late L2 bilingual group had a minimum of 7 years residing in the US; several of these participants had resided there for well over a decade. The members of this group, many of whom are in fact parents to HSs, embody the profile of the input providers to HSs, that is, the possibly attrited bilinguals whose input quality Sorace (2012) discussed. The experimental group of HSs $(n=63)$ was further divided into two sub-groups based on a standardized proficiency test: an advanced HS group ( $n=29$, mean age 20.2, 23 females, 6 males), and an intermediate HS group ( $n=34$, mean age 19.6, 27 females, 7 males). Seventeen HSs were born in the US; the rest migrated there in early childhood. The mean arrival age was 1.9 years.

\subsection{Procedure}

All HS participants took the felicity judgment task under supervision in a research laboratory (50-min session); they completed the questionnaire and the proficiency test online on their own time. HS participants took part in the experiment for partial class credit. The investigators did not know the names of the participants; each test was identified by a numerical code only. The monolingual group completed all portions of the experiment via the Internet.

The independent measure of proficiency that was used to divide the HS group consisted of fifty multiple-choice items focusing on vocabulary and grammar (maximum possible score $=50$ ). This test is based on a simplified version of the DELE (Diploma de Español como Lengua Extranjera, the official Spanish language accreditation issued by the Ministry of Education, Culture and Sport of Spain) and has been used successfully in prior generative L2 Spanish research (e.g., Montrul, 2004; White et al., 2004). The accuracy range cutoffs were 40-47 for the advanced HS group and 30-39 for the intermediate HS group. ${ }^{9}$

Because syntactic knowledge of clitics was a logical prerequisite for comprehending clitic-doubled dislocations, we used a multiple-choice clitic test. The clitic test, which consisted of 10 multiple-choice items for a maximum of 50 points (see Appendix A for an example), was administered after the main experimental task in order to avoid priming effects. A context dialog item preceded each multiple-choice item and was followed by a question, the answer to which required the use of accusative clitics. The answer choices included five different options, some of which were ungrammatical due to the position of the clitic in relation to the verb. In order to be included in the study, each participant had to achieve at least $70 \%$ accuracy (35/50). All HS participants showed knowledge of the syntax of clitics, resulting in zero exclusions. Lastly, all participants answered a detailed background questionnaire describing their language learning history and use as well as (non-identifying) demographic information.

Our main task was an untimed, audio-visual felicity judgment task. Each test item was entirely in Spanish (text and audio recording) and included a context followed by a short dialog: a short question and two possible answers, which differed in the presence/absence of the clitic in the conditions discussed in this study. Five native speakers from various countries (Chile, Colombia, Mexico, and Honduras; 3 males, 2 females) recorded the test items in order to avoid any intonation coercions. ${ }^{10}$ The decision to include audio recordings was crucial because the dislocated structures under investigation have special intonation patterns. While (Contrastive) Fronted Focus has emphatic stress on the fronted constituent, CLLD lacks this stress. In this respect, the difference between these two constructions includes both the clitic and the intonation. If the presentation were only written, the participants could reject certain structures for the wrong reasons. For example, a context-test sentence combination for Fronted Focus could be rejected as infelicitous if participants failed to mentally assign the proper emphatic stress.

Participants evaluated the felicity of each answer on a 4-point Likert scale, ranging from "Perfect" to "Very strange." Participants were also provided with an "I don't know" option. A total of thirty-one "I don't know" and blank answers were excluded from the analysis, resulting in the exclusion of less than $1 \%$ of the data $(0.58 \%)$. The task included 40 context-test sentence combinations in the following conditions: (a) 5 Identity CLLD; (b) 5 Set-Subset CLLD; (c) 5 Fronted Focus constructions; (d) 5 Corrective Focus CLRD; (f) Ambiguous CLRD 5; (g) 5 Rheme constructions; and (h) 10 fillers. In this article, we report the results of the first three conditions only (CLLD, Set-Subset and Identity, and Fronted Focus).

\footnotetext{
${ }^{9}$ Mean performance in the proficiency was 33.7 for the Intermediate HS group (SD 3.72), while the mean for the Advanced HS group was 42.95 out of 50 (SD 1.93).

${ }^{10}$ We intentionally excluded Peninsular Spanish varieties given that we assumed that HS would be less familiar with them. This assumption was corroborated by the information we gathered in the participants' language background questionnaire.
} 
A sample test item for the CLLD Set-Subset condition is presented below. The question immediately following the context mentions pescado 'fish' which is the set of the subset salmon 'salmon'. The first answer (a), which includes the clitic, was expected to be felicitous, given that CLLD is possible with relations other than identity (set-superset and partwhole). On the other hand, while option (b) without a clitic is grammatical (being a FF construction, as indicated by lack of clitic paired with the emphatic stress in the audio recording), it is infelicitous in this context, so we expected participants to reject it.

\section{(6) CLLD, Set-Subset}

Juan y su hermana Sofía están en un restaurante japonés. Juan nunca ha comido comida japonesa, así que no está seguro de qué pedir. Decide preguntarle a Sofía.

Juan and his sister Sofía are at a Japanese restaurant. Juan has never had Japanese food before, so he is not quite sure what to order. He decides to ask Sofía.

Juan: $\quad$ ¿Has probado el pescado de aquí?

"Have you tried the fish here?"

(a) Sofía: $\quad \sqrt{ }$ El salmón lo probé la semana pasada. Estaba delicioso.

(b) Sofía (b): \#El salmón probé la semana pasada. Estaba delicioso.

the salmon l-tried the week last. It-was delicious.

Before discussing our results, we would like emphasize the importance of our experimental design on our subsequent interpretations. As example (6) shows, the pattern of the experimental items in the CLLD conditions consisted of $\checkmark$ clitic/ *no clitic. One may claim that this pattern could be superficially learned and that speakers did not need to integrate the contextual information. However, our experimental design is such that both sentences ( $a$ and $b$ ) were felicitous in the right context. Every single experimental item was in fact grammatical: only felicity differed. The items without the clitic are actually Fronted Focus (FF) constructions, which are grammatical and can be felicitous in a context when the dislocated element is used for corrective focus. Example (7) constitutes an item in the FF condition.

\section{(7) FF sample item}

Juan y Mónica invitaron a María a comer. La cena se sirvió en la terraza y todo estaba muy rico. María felicitó a Juan por la sopa que había hecho. Cuando Mónica escucha esto, responde:

Juan and Mónica invited Maria for dinner. Dinner was served on the terrace and everything was very tasty. Maria complimented Juan on the soup he cooked. When Monica hears this, she responds:

Mónica: LA CARNE preparó Juan, no la sopa.

the meat prepared Juan neg the soup.

Mónica: *LA CARNE la preparó Juan no la sopa.

Thus, the accurate pattern for the FF condition ( ${ }^{*}$ litic/ $/$ no clitic) was exactly the opposite of the CLLD condition. The integration of context was absolutely crucial for accurate felicity judgments.

\subsection{Results}

For clarity, the CLLD results are presented first, organized by semantic condition (Set-subset and Identity). The FF results are presented subsequently. The results for CLRD and Rheme are not reported here for space reasons. However, the reader should note that all of these conditions acted as counterbalance for one another in the test. The analyses used general linear model ANOVAs with repeated measures to compare the ratings for each construction included in the study. Our main focus was to find significant contrasts between ratings to acceptable and unacceptable test sentences within each group of participants, given that our goal was to determine whether each group showed sensitivity to the appropriateness of each construction. Additionally, we ran pairwise comparisons within conditions with the ratings of each group.

\subsubsection{CLLD Group results}

Fig. 2 displays all mean group ratings for the CLLD identity condition, while Fig. 3 represents the responses for CLLD Set-Subset (see example test item in (6)). Following the context, participants evaluated the answers with clitics (which were expected to be felicitous) and the answers without clitics (which were expected to be infelicitous) independently of 


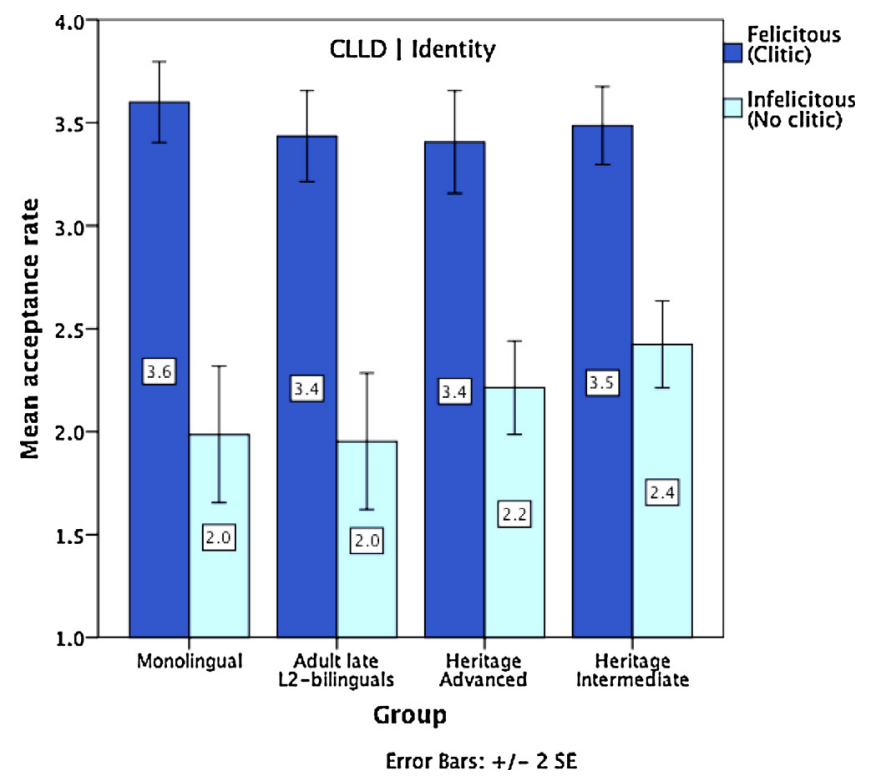

Fig. 2. Mean ratings of CLLD-Identity acceptability in context.

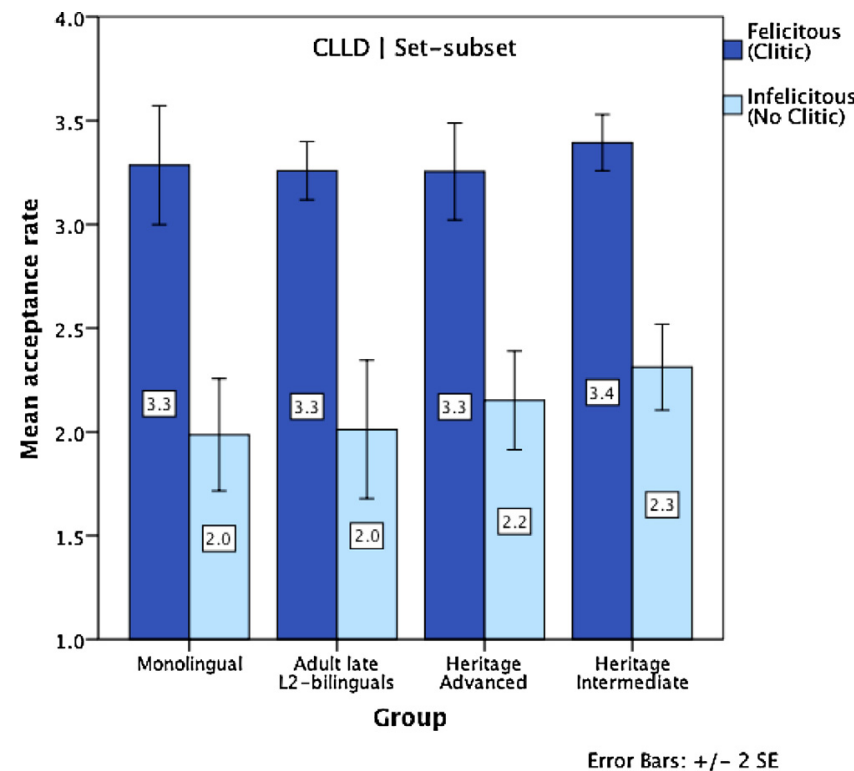

Fig. 3. Mean ratings of CLLD Set-Subset acceptability in context.

each other. A two-way repeated-measures ANOVA was performed with type of sentence (Identity, Set-Superset) and appropriateness (clitic $\checkmark$ and without clitic \#) as within-participants variables and group as a between-participants variable. A significance level of $p<0.5$ was established. There was a significant effect of type of sentence $(F(1,90)=13.6, p<0.0001)$, and an effect of appropriateness $(F(1,90)=371.3, p<0.0001)$, but no effect of participant group (native monolinguals, adult L2 bilinguals, heritage advanced, heritage intermediate; $F(3,90)=1.306, p<0.277$ ). Additionally, the interaction between type and group was not significant $(F(6,258)=1.455, p<0.239)$. The only other significant interaction was between type and acceptability $(F(1,90)=7.727, p<0.007)$. We looked into the significant interaction further.

Sidak pairwise comparisons within the acceptable sentences revealed that the participant groups treated the two types of CLLD, with and without identity between antecedent and dislocate, differently. They preferred the CLLD with identity to the one where the antecedent and the dislocated constituent were in a Set-Subset relationship $(p=.0001)$. However, this was not the case for the unacceptable sentences $(p=.460)$. In other words, they rejected the cliticless sentences equally resolutely for the identity and for the Set-Subset conditions. 
Table 2

Number of individuals who demonstrated a contrast between felicitous and infelicitous CLLD sentences (percentages in parentheses).

\begin{tabular}{llr}
\hline Participant groups & $\checkmark$ CLLD - Identity & $\checkmark$ CLLD - Set-Subset \\
\hline Monolingual & $14 / 14(100 \%)$ & $11 / 14(79 \%)$ \\
L1-attrited/adult L2 bilingual & $14 / 17(82 \%)$ & $13 / 17(76 \%)$ \\
Heritage Advanced & $21 / 29(72 \%)$ & $20 / 29(69 \%)$ \\
Heritage Intermediate & $21 / 34(62 \%)$ & $21 / 34(62 \%)$ \\
\hline
\end{tabular}

The most important result, we would like to emphasize, is that all of the participant groups behaved essentially in the same way; that is, there was no significant interaction among Type, Grammaticality, and Group. These results suggest that, like the native control groups (late adult bilingual and monolingual), both of the HS groups (advanced and intermediate) successfully made all the relevant distinctions between the infelicitous and felicitous sentences for CLLD.

\subsubsection{Individual results}

Given that the distinctions between the felicitous and infelicitous sentences are rather subtle (both options are grammatical but only one is felicitous in the right context), and in the absence of differences between the participant groups, we examined the data looking at individual performances in order to find any evidence of interpersonal variation. For an individual participant to be considered successful in differentiating acceptable from unacceptable sentences, he or she had to have scores that differed by a full point (out of four) in the correct direction. Table 2 displays the number of individual participants per group who demonstrated knowledge of the felicity distinction, using this criterion. It is interesting to note that although there are no statistically significant distinctions among the groups, the individual results show modest differential patterns in the two CLLD conditions. As expected, most control speakers in both the monolingual and the late L2 bilingual groups made the distinction, while the two heritage groups were less accurate, a fact that correlated with their proficiency. In addition, it seems that the monolingual natives are more secure in accepting the appropriate test sentence when the antecedent and dislocate are identical. For the rest of the groups, the semantic relationship of antecedent and dislocate does not appear to matter. These subtle distinctions underscore the fact that it is vital to present individual data because group results necessarily mask some of the inherent individual variation.

\subsubsection{FF Group results}

Fig. 4 displays the mean acceptability judgments for FF. In this condition, a repeated measures ANOVA revealed an effect of Grammaticality $(F(1,90)=87.13, p<.0001)$, but no significant interaction between Group and Grammaticality $(F(3,90)=0.511, p<.675)$. Post hoc Sidak tests showed no differences between the groups. Pair-wise comparisons

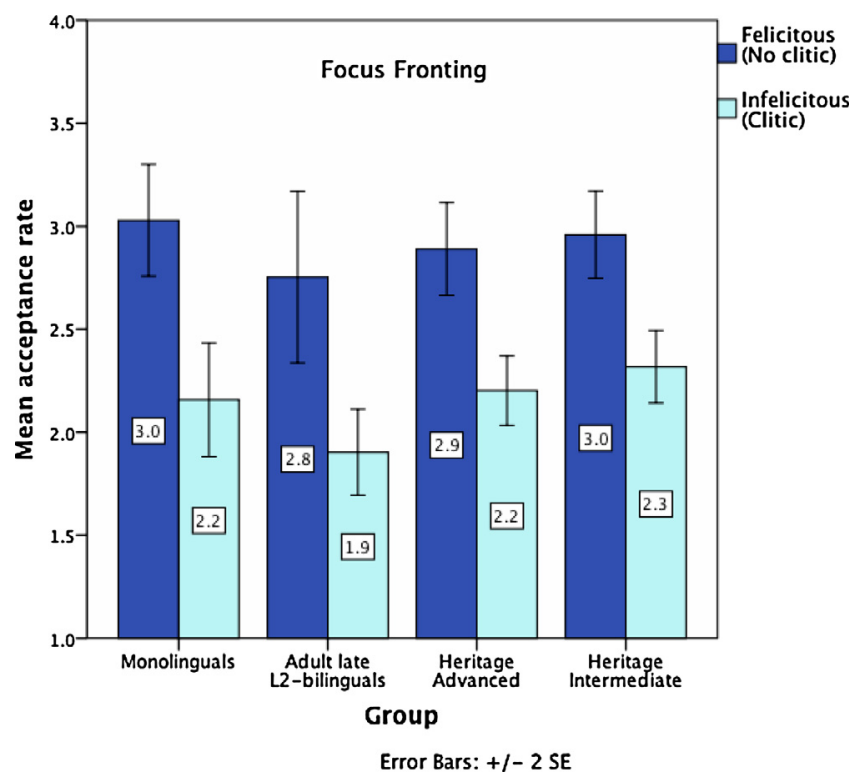

Fig. 4. Mean ratings of Fronted Focus acceptability in context. 
demonstrated that every group made a significant distinction $(p<.0001$ for all groups) between FF grammatical (no clitic) and ungrammatical sentences (clitic). These results are the mirror image of the CLLD results:

\section{Discussion}

Our experimental study looks at two syntactic structures at the discourse-syntax interface: Clitic Left Dislocation (CLLD) and Fronted Focus (FF). CLLD establishes an anaphoric relation to an antecedent mentioned in the previous discourse and requires an accusative clitic doubling the dislocated object, while FF does not allow such anaphoric relationships. In each context-test sentence combination, we presented one felicitous option and one infelicitous option. These options were presented in writing as well as in audio format to avoid intonation coercions. We also examined knowledge of the semantic freedom of the antecedent-dislocate relationship by testing CLLD with identity and Set-Subset relations between the dislocated constituent and its antecedent.

Our results showed a high degree of convergence (clear differentiation between felicitous and infelicitous choices) from all the participant groups in all the conditions. As Figs. 2-4 show, all groups accurately and reliably distinguished between acceptable and unacceptable examples of the CLLD construction as well as in the FF condition. We highlight the fact that there is no proficiency effect in our data: the intermediate HSs show knowledge indistinguishable from the rest of the natives. CLLD has been examined before in the context of the IH with L2 learner groups of different proficiency levels (Ivanov, 2012; Valenzuela, 2005; Slabakova et al., 2012), with most of the results showing successful acquisition of the properties at the advanced levels (see Slabakova and Ivanov, 2011 for a reanalysis of Valenzuela's data). In our study, we found that HSs were as accurate as monolinguals, with no significant differences between the groups in either semantic condition (Identity and Set-Subset). Advanced L2ers can also successfully acquire FF (Slabakova et al., 2012).

These results are interesting beyond what they show us for HS knowledge of CLLD and reference more generally, given the general trend in HS studies of focusing on domains of difference as opposed to domains of similarity between monolinguals and HSs. What these results show is that discourse-sensitive clitic-doubled dislocations and fronting operations were acquired during the course of HSs' naturalistic development of the language. This suggests that the triggers are robustly and unambiguously present in the input the HSs received and that this domain may be rather resistant to attrition. This is further supported by the global lack of difference between the monolinguals and the bilingual controls, since no signs of attrition were witnessed in the latter group's performance.

There is a subtle performance difference that deserves discussion. This relates to how acceptable the CLLD sentences are when the antecedent and the dislocated object are not exactly identical. The unacceptable sentences in both the Identity and the Set-Subset conditions of our study were reliably rejected, with no differences between the participant groups. The rate of acceptance between the two types of CLLD, however, was different in the monolingual group. The monolingual native speakers accepted Identity CLLD with a mean of 3.6 out of 4 , while they accepted Set-Subset CLLD with a mean rating of 3.3. None of the other groups differentiate between the two acceptable types of sentence. It could be the case that CLLDs with identical antecedent and dislocate are more frequent than CLLDs with free semantic relations between them, and the monolinguals are sensitive to this distinction, while the rest of the groups are not. Unfortunately, no corpus study in Spanish describes this semantic freedom within CLLD quantitatively. However, we believe that the statistical distinction we described does not amount to the monolingual and the bilingual/L1-attriter groups performing differently. We point to the significant contrasts between acceptable and unacceptable sentences in each condition, for all groups, as our main result.

Let us return to the two opposing hypotheses offered in Section 4. Hypothesis A claimed that if we found differences across all the groups, this would constitute evidence in support of the $\mathrm{HH}$, whereas Hypothesis $B$ claimed that failure to show significant differences would be inconsistent with the predictions of the $\mathrm{IH}$. To be most relevant, we took heed of the recent discussion of whether or not the IH should be applicable a priori to HS acquisition, stemming from Sorace's (2011) exclusion of HSs. Sorace's (2012) answer acknowledges that HSs are indeed an important test case for the IH provided that issues related to cross-generational attrition effects are eliminated as a possible variable so as not to obscure the source of possible differences. Taking this caveat seriously, we included two types of controls: Monolingual native Spanish speakers and Spanish-English bilinguals (native speakers of Spanish, adult L2 learners of English). The latter group are not only the primary providers of input to the HS generation but also constitute a group for which the $\mathrm{IH}$ predicts attrition for these structures, because these bilinguals live in a language contact situation, outside of their native environment.

Our results did not show any significant differences between the two control groups; therefore we believe it is justified to claim that, after at least 7 years of residing in the US, the late L2 bilingual control group does not show evidence of L1attrition in this domain. Although admittedly based on indirect evidence, we also take this lack of difference to indicate that the input these speakers provide to HSs in this domain is not affected by cross-generational attrition. As such, we have uncovered a domain in which it is valid to test the $\mathrm{IH}$ using $\mathrm{HS}$ data, according to the guidelines provided by Sorace (2012). 
As we saw in greater detail in the previous section, the data unambiguously show that all four participant groups make the expected contrasts for CLLD and FF while doing so-statistically-to the same degree. Therefore, we maintain that the data from this study are supportive of Hypothesis B. Namely, the lack of differences across the monolingual group and all three bilingual groups seems to be inconsistent with the $\mathrm{IH}$ insofar as it predicts some level of residual optionality in structures of this type. We cannot support the $\mathrm{IH}$ with these results since we find no such evidence. However, we need to keep in mind that the $\mathrm{IH}$ makes claims specifically related to the coordination of syntactic and pragmatic/contextual information in real time. In other words, in these domains, the IH does not claim that bilingual grammars are destined to have representational problems per se. It is possible that our methodology is simply unable to detect a more fine-grained underlying difference as related to real-time coordination. But we must also keep in mind that the claims of the $\mathrm{IH}$ are built upon work that did not employ processing measures, but rather used experiments very similar in design to ours. For example, Sorace and colleagues' seminal work on referential subject distribution found differences using only offline tasks (e.g. Tsimpli and Sorace, 2006), evidence which was used as the cornerstone of the hypothesis at the time. So the question of why we do not find even small differences lingers and is relevant.

Viewing our work alongside other work examining context felicitousness with clitic dislocated structures in other bilingual populations (e.g. Donaldson, 2011; Ivanov, 2012; Slabakova et al., 2011, 2012) allows us to question whether or not the $\mathrm{IH}$ is as explanatory as it purports to be. Although it is true that we cannot directly weigh in on the processing side of the $\mathrm{IH}$, we believe, having found no behavioral traces of any difference between these populations and in accord with other complimentary studies as cited above, that we provide evidence to show that not all interface properties are equally subject to vulnerability. If this interpretation is on the right track, then the IH should inform us in a principled manner why this should be (cf. Rothman and Slabakova, 2011). If it turns out to be the case, as we believe our data suggest, that some interface properties are simply more problematic than others-subject distribution is more vulnerable than clitic dislocation structures, for example-then we are essentially back to understanding asymmetries in acquisition convergence on a property-by-property basis, even at external interfaces (cf. White, 2011). This interpretation effectively questions the explanatory nature of the $\mathrm{IH}$.

In this article, we investigated whether monolingual and bilingual native speakers of Spanish were equally sensitive to the discourse appropriateness of Clitic Left Dislocation and Fronted Focus, two syntax-discourse interface constructions that associate syntactic computations with discourse monitoring. In order to test the predictions of the IH, we compared the monolingual and bilingual controls (possible L1 attriters) to heritage speakers of Spanish of two proficiency levels (Advanced and Intermediate). Our results show that all four experimental groups performed equally well, and in accordance with the expectations defined in the literature. These results are not predicted by the $\mathrm{IH}$ and effectively question the extent of its explanatory power. HSs have been found to perform differently (via offline tasks) from monolingual natives with internal interface properties as well, so the claim that external interface properties are more difficult to acquire is not supported by our data.

We should note that while our results are not supportive of the $\mathrm{IH}$, the question of whether performance would decline in online tasks remains. If, using online tasks, HSs fail to show differences in the predicted areas the way near-native L2 speakers do, this could be explained by the greater inhibitory control HSs might have developed (via more practice) during the longer time they have been bilingual. This interesting question, which could only be addressed using online methodologies, should be addressed in future research.

\section{Appendix A. Supplementary data}

Supplementary data associated with this article can be found, in the online version, at http://dx.doi.org/10.1016/j. lingua.2014.01.002.

\section{References}

Au, T., Knightly, L., Jun, S., Oh, J., 2002. Overhearing a language during childhood. Psychological Science 13, $238-243$.

Belletti, A., Bennati, E., Sorace, A., 2007. Theoretical and developmental issues in the syntax of subjects: evidence from near-native Italian. Natural Language and Linguistic Theory 25 (4), 657-689.

Bialystok, E., 2009. Bilingualism: the good, the bad and the indifferent. Bilingualism: Language and Cognition 12, 3-11.

Casielles-Suárez, E., 2004. The Syntax-Information Structure Interface: Evidence from Spanish and English. Routledge, New York.

Chomsky, N., 2001. Derivation by phase. In: Kenstowicz, M. (Ed.), Ken Hale: A Life in Language. MIT Press, Cambridge, MA, pp. 1-51.

Donaldson, B., 2011. Left-dislocation in near-native French. Studies in Second Language Acquisition 33, 399-432.

Fodor, J.A., 1983. The Modularity of Mind. MIT Press, Cambridge, MA.

Green, D.W., 1986. Control, activation, and resource: a framework and a model for the control of speech in bilinguals. Brain and Language 27 (2), 210-223.

Hart, B., Risley, T.R., 1995. Meaningful Differences in the Everyday Experience of Young American Children. Brookes Publishing Company, Baltimore, MD. 
Ivanov, I., 2012. L2 acquisition of Bulgarian clitic-doubling: a test case for the Interface Hypothesis. Second Language Research 28 (3), 345-368. Jackendoff, R., 2002. Foundations of Language: Brain, Meaning, Grammar Evolution. Oxford University Press, New York.

López, L., 2009. A Derivational Syntax for Information Structure. Oxford University Press, New York.

Marian, V., Spivey, M., Hirsch, J., 2003. Shared and separate systems in bilingual language processing: converging evidence from eye-tracking and brain imaging. Brain and Language 86 (1), 70-82.

Montrul, S., 2004. Subject and object expression in Spanish heritage speakers: a case of morphosyntactic convergence. Bilingualism: Language and Cognition 7 (2), 125-142.

Montrul, S., 2008. Incomplete Acquisition in Bilingualism: Re-examining the Age Factor. John Benjamins, Amsterdam.

Montrul, S., Polinsky, M., 2011. Why not heritage speakers? Linguistic Approaches to Bilingualism 1 (1), 58-62.

Montrul, S., Potowski, K., 2007. Command of gender agreement in school-age Spanish-English bilingual children. International Journal of Bilingualism 11 (3), 301-328.

Pascual y Cabo, D., Rothman, J., 2012. The (II)Logical problem of Heritage Speaker bilingualism and incomplete acquisition. Applied Linguistics $33,450-455$.

Piller, I., 2001. Who, if anyone, is a native speaker. Anglistik: Mitteilungen des Verbandes Deutscher Anglisten 12 (2), $109-121$.

Pires, A., Rothman, J., 2009. Disentangling sources of incomplete acquisition: an explanation for competence divergence across heritage grammars. International Journal of Bilingualism 13 (2), 211-238.

Polinsky, M., 1997. American Russian: Language loss meets language acquisition. In: Proceedings of the Annual Workshop on Formal Approaches to Slavic Linguistics, pp. 370-406.

Polinsky, M., 2007. Incomplete acquisition: American Russian. Journal of Slavic Linguistics 14, 191-262.

Polinsky, M., 2011. Reanalysis in adult heritage language. Studies in Second Language Acquisition 33 (02), $305-328$.

Rothman, J., 2007. Heritage speaker competence differences, language change and input type: inflected infinitives in Heritage Brazilian Portuguese. International Journal of Bilingualism 11, 359-389.

Rothman, J., 2008. Linguistic epistemology and the notion of monolingualism. Sociolinguistic Studies 2 (3), 441-457.

Rothman, J., 2009. Pragmatic deficits with syntactic consequences? L2 pronominal subjects and the syntax-pragmatics interface. Journal of Pragmatics 41 (5), 951-973.

Rothman, J., Slabakova, R., 2011. The mind-context divide: on linguistic interfaces and language acquisition. Lingua 121 (4), 568-576.

Rothman, J., Treffers-Daller, J., 2014. A prolegomenon to the construct of the native speaker: heritage speaker bilinguals are natives too! Applied Linguistics.

Silva-Corvalán, C., 1994. Language Contact and Change: Spanish in Los Angeles. University Press, Oxford.

Slabakova, R., Ivanov, I., 2011. A more careful look at the syntax-discourse interface. Lingua 121, 637-651.

Slabakova, R., Rothman, J., Kempchinsky, P., 2011. Gradient competence at the syntax-discourse interface. EUROSLA Yearbook 11, 218-243.

Slabakova, R., Kempchinsky, P., Rothman, J., 2012. Clitic-doubled left dislocation and focus fronting in L2 Spanish: a case of successful acquisition at the syntax-discourse interface. Second Language Research 28 (3), 319-343.

Sorace, A., 2004. Native language attrition and developmental instability at the syntax-discourse interface: data, interpretations and methods. Bilingualism: Language and Cognition 7 (2), 143-145.

Sorace, A., 2011. Pinning down the concept of 'interface' in bilingualism. Linguistic Approaches to Bilingualism 1 (1), 1-33.

Sorace, A., 2012. Pinning down the concept of interface in bilingual development: a reply to peer commentaries. Linguistic Approaches to Bilingualism 2 (2), 209-217.

Sorace, A., Serratrice, L., Filiaci, F., Baldo, M., 2009. Discourse conditions on subject pronoun realization: testing the linguistic intuitions of older bilingual children. Lingua 119 (3), 460-477.

Spivey, M.J., Marian, V., 1999. Cross talk between native and second languages: partial activation of an irrelevant lexicon. Psychological Science 10 (3), 281-284.

Suskind, D., Leffel, K.R., Hernandez, M.W., Sapolich, S.G., Suskind, E., Kirkham, E., Meehan, P., 2013. An Exploratory Study of "Quantitative Linguistic Feedback" Effect of LENA Feedback on Adult Language Production. Communication Disorders Quarterly 34 (4), $199-209$.

Toribio, A., 2001. On Spanish language decline. In: Proceedings of the 25th Boston University Conference on Language Development. Cascadilla Press, Sommerville, MA, pp. 768-779.

Tsimpli, I.M., Sorace, A., 2006. Differentiating interfaces: L2 performance in syntax-semantics and syntax-discourse phenomena. In: Proceedings of the 30th Annual Boston University conference on language development, pp. 653-664.

Tsimpli, I., Sorace, A., Heycock, C., Filiaci, F., 2004. First language attrition and syntactic subjects: a study of Greek and Italian near-native speakers of English. International Journal of Bilingualism 8 (3), 257-277.

Valenzuela, E., 2005. L2 ultimate Attainment and the Syntax-Discourse Interface: The Acquisition of Topic Constructions in Non-native Spanish and English. (Unpublished Ph.D. dissertation) McGill University, Canada.

Valenzuela, E., 2006. L2 end state grammars and incomplete acquisition of Spanish CLLD constructions. In: Slabakova, R., Montrul, S., Prévost, P. (Eds.), Inquiries in Linguistic Development: In Honor of Lydia White. John Benjamins, Amsterdam, pp. 283-304.

Villalba, X., 2000. The Syntax of Sentence Periphery. Publicacions de la Universitat Autònoma de Barcelona.

White, L., 2011. The interface hypothesis: how far does it extend? Linguistic Approaches to Bilingualism 1, 108-110.

White, L., Valenzuela, E., Kozlowska-MacGregor, M., Leung, Y.K., 2004. Gender and number agreement in nonnative Spanish. Applied Psycholinguistics 25, 105-133. 